Supporting Information for

\title{
"Mechanism of Cyanine5 to Cyanine3 photoconversion and its application for high-density single-particle tracking in a living cell"
}

Yoonjung Cho ${ }^{1 \ddagger}$, Hyeong Jeon $\mathrm{An}^{2 *}$, Taehoon Kim ${ }^{1}$, Chulbom Lee ${ }^{1 *}$ and Nam Ki Lee ${ }^{*}$

${ }^{1}$ Department of Chemistry, Seoul National University, Seoul 08833, Republic of Korea

${ }^{2}$ Department of Physics, Pohang University of Science and Technology, Pohang 37673, Republic of Korea

$\$$ These authors contributed equally

*To whom correspondence should be addressed. E-mail: namkilee@snu.ac.kr (NKL) or chulbom@snu.ac.kr (CL). 


\section{Materials and Methods}

\section{Ensemble photoconversion of Cyanine dyes}

For the photoconversion of three cyanine dyes, sulfo-Cy5 carboxylic acid, sulfo-Cy5.5 carboxylic acid (Lumiprobe, USA), and AF 647 carboxylic acid (Invitrogen, USA), the samples were dissolved in distilled water, with the final concentration of each solution adjusted to $0.5 \mathrm{mM}$. The dye solution in a quartz vial was irradiated with a $642 \mathrm{~nm}$ laser (VFL-P-1000-642, MPB communications, Canada) at a power of $300 \mathrm{~mW}$ for 8 hours under stirring. Steady-state fluorescence spectra were recorded during the photoconversion reaction using a fluorescence spectrophotometer (Cary Eclipse, Agilent, USA) with excitation at $520 \mathrm{~nm}$.

\section{High-Pressure Liquid Chromatography (HPLC)-based Purification and Quantification.}

HPLC-based separations were performed on an Agilent 1100 Infinity HPLC with Eclipse Plus C18 $3.57 \mu \mathrm{m}$ (4.6 $100 \mathrm{~mm}$ ) using a photodiode array detector. The eluents were (A) $0.1 \%$ TFA in water, (B) $0.1 \%$ TFA in acetonitrile, (C) $50 \mathrm{mM}$ TEAA (pH 7) in water, and (D) acetonitrile, and the gradient method was from 5\% B to $100 \% \mathrm{~B}$ in $\mathrm{A}$ (from $5 \% \mathrm{D}$ to $100 \% \mathrm{D}$ in $\mathrm{C}$ ) over $28 \mathrm{~min}$ at a flow rate of $1.0 \mathrm{~mL} / \mathrm{min}$. The eluent system was employed differentially depending on the chemical structure of each dye. For further photophysical and structural analysis, speed vac. or freeze-drying (FD8508, iLShinBioBase, Republic of Korea) was used to remove the buffer.

HPLC-based quantification was performed on an Agilent 1260 Infinity HPLC with Poroshell 120 EC-C18 $2.7 \mu \mathrm{m}(4.6 \times 50 \mathrm{~mm})$ using a photodiode array detector. The gradient method was from $5 \% \mathrm{~B}$ to $100 \% \mathrm{~B}$ in $\mathrm{A}$ over $28 \mathrm{~min}$ at a flow rate of $0.5 \mathrm{~mL} / \mathrm{min}$ with a $5 \mu \mathrm{L}$ injection volume. The relative amount of the sample was quantified against the integrated area of the peak $\left(\lambda_{\mathrm{abs}}=547 \mathrm{~nm}\right)$.

\section{Liquid chromatography and high-resolution mass spectrometry}

High-resolution LC/MS was performed using an Ultimate 3000 (Thermo Scientific, USA) - Triple TOF 5600 (AB Sciex, USA) with a Waters Cortecs C18 $1.6 \mu \mathrm{m}(2.1 \mathrm{~mm}$ x $150 \mathrm{~mm})$. The eluents were (A) $0.1 \%$ formic acid in water and (B) $0.1 \%$ formic acid in acetonitrile, and the gradient method was from $5 \% \mathrm{~B}$ to $25 \% \mathrm{~B}$ in $\mathrm{A}$ over $10 \mathrm{~min}$ at a flow rate of $0.3 \mathrm{~mL} / \mathrm{min}$. Electrospray ionization (ESI) was used with an ion spray voltage floating of $5.5 \mathrm{kV}$, a collision energy of 10 , and a desolvation temperature of $500{ }^{\circ} \mathrm{C}$. The detector was operated in a positive or negative mode depending on the chemical structure of each dye. High-resolution MS/MS 
experiments were performed using the same instrument and gradient method, except that the collision energy was 35.

\section{Characterization of optical properties of dye}

The optical properties of the photoconverted dyes, parent dyes, and reference dyes were characterized by measuring the fluorescence and absorption spectra in distilled water using a UV-Vis spectrophotometer (DU 730 Beckman Coulter, USA) and the fluorescence spectrophotometer mentioned above.

\section{Labeling of DNA}

DNA oligonucleotides (HPLC purified) were purchased from Integrated DNA Technologies (IDT, USA), where 3AmMo and 5AmMC6 indicate 3' and 5' end-positioned amine modifications, respectively, and 3Bio indicates a biotin modification for surface immobilization.

DNA I AGA TCT CGA GTC GGC AGC GA (T)n/3AmMO/, where $\mathrm{n}=0$, 20, and 40

DNA II /5AmMC6/TCG CTG CCG ACT CGA GAT CT/3Bio/

DNA oligonucleotides were labeled with amine-reactive dyes (Cy3, Cy5, AF647) according to the manufacturer's instructions. The dye-labeled oligonucleotides were purified from unreacted free dyes by ethanol precipitation. The labeling efficiency was determined by UV-Vis spectrometry and was typically more than $95 \%$. DNA I was labeled with $\mathrm{Cy} 5$ or $\mathrm{Cy} 3$, and the complementary strand DNA II was either left unlabeled or labeled with Cy5. The complementary strands of DNA were annealed to form double-stranded DNA by mixing $500 \mathrm{nM}$ aliquots of each strand in $10 \mathrm{mM}$ Tris- $\mathrm{HCl}(\mathrm{pH} 7.5)$ and $250 \mathrm{mM} \mathrm{NaCl}$, heating to 90 ${ }^{\circ} \mathrm{C}$ for 2 minutes, and slowly cooling to room temperature.

\section{Labeling of antibody}

EGFR monoclonal antibody (AHR5072 Invitrogen) and ErbB2 monoclonal antibody (OP39, Sigma-Aldrich, Germany) were labeled with amine-reactive Cy5 or AF647. The labeling reaction was carried out in sodium tetraborate buffer $(0.1 \mathrm{M}, \mathrm{pH} 8.5)$ for more than 12 hours at $4{ }^{\circ} \mathrm{C}$ and purified by a size exclusion column (PD Minitrap Sephadex G-25 or PD-10, GE Healthcare, USA) to remove excess dye. The degree of labeling of antibodies with dyes was determined by UV-Vis spectrophotometry using the extinction coefficients of the antibody and the fluorophore. 


\section{NMR spectroscopy}

${ }^{1} \mathrm{H}$ NMR spectra were recorded on an Agilent vrms-500 magnetic resonance system (499 MHz) spectrometer. Chemical shifts are reported in parts per million ( $\mathrm{ppm}$ ) relative to tetramethylsilane (TMS) using the residual protio-solvent as an internal standard (DMSO-D $\left.6,{ }^{1} \mathrm{H}: 2.50 \mathrm{ppm}\right)$. Data for ${ }^{1} \mathrm{H}$ NMR are reported as follows: chemical shift $(\delta, \mathrm{ppm})$, multiplicity (s, singlet; d, doublet; t, triplet; q, quartet; dd, doublet of doublet; m, multiplet), coupling constants $(\mathrm{J}, \mathrm{Hz})$, integration and assignments.

\section{Fluorescence microscopy and imaging acquisition}

Fluorescence imaging was performed on a home-built objective-type total internal reflection fluorescence microscope (TIRFM) based on a Nikon Eclipse Ti-E inverted microscope with a Perfect Focus System. Shuttercontrolled lasers, including a $532 \mathrm{~nm}$ laser (for $\mathrm{Cy} 3$ and photoconverted products, Cobolt Dual Calypso, Cobolt, Sweden), a $642 \mathrm{~nm}$ laser (for Cy5 and AF647), a $561 \mathrm{~nm}$ laser (for photoconversion and single-particle tracking of AF647, YLK 6150T, Lasos, Germany), and a $405 \mathrm{~nm}$ laser (for activation of AF647, DL-405-120, Crystal Laser, USA), were collimated and focused on the back focal plane of an oil-immersion objective lens (CFI Apo TIRF 100×, numerical aperture 1.49). The emission light was separated by a dichroic mirror (ZT 405/488/561/640rpcv2 and ZT532/640rpc, Chroma, USA) and emission filters (ET665lp and ET590/50m, Chroma) and collected using an electron multiplying charge-coupled device (EM-CCD) camera (iXon Ultra 888, Andor Technology, United Kingdom). For higher magnification, a 1.5x amplifier was used.

The pre-converted dyes were probed with $5-10 \mathrm{~W} / \mathrm{cm}^{2}$ of a $532 \mathrm{~nm}$ laser for $100 \mathrm{~ms}$ time exposure. Then, Cy5 or AF647 was converted by illuminating a $642 \mathrm{~nm}$ laser continuously with an intensity of $0.5-3 \mathrm{~W} / \mathrm{cm}^{2}$, and the photoconverted fluorophores were probed with an intensity of $5-10 \mathrm{~W} / \mathrm{cm}^{2}$ after 45 seconds by a shuttercontrolled $532 \mathrm{~nm}$ laser for $100 \mathrm{~ms}$. Metamorph Software was used to control the measurements and maintain focus during data acquisition.

\section{Single-molecule Imaging}

For single-molecule imaging, quartz slides and coverslips were coated with polyethylene glycol (PEG) and 2\% biotinylated PEG to block nonspecific binding of samples. An imaging chamber was assembled with PEGylated slides and coverslips using adhesives and double-sided tape.

Biotin-modified DNA was immobilized on the glass surface via neutravidin-biotin interactions. All imaging was performed at room temperature in buffer A (10 mM Tris-HCl, $10 \mathrm{mM} \mathrm{NaCl}, \mathrm{pH}$ 7.5). For singlet oxygen- 
depleted conditions, $1 \mathrm{mM}$ Trolox (TX), $1 \mathrm{mM} \beta$-mercaptoethylamine (MEA), or an oxygen scavenging system $(1 \mathrm{mg} / \mathrm{ml}$ glucose oxidase, $0.04 \mathrm{mg} / \mathrm{ml}$ catalase, and $0.4 \%(\mathrm{w} / \mathrm{v}) \beta$-D-glucose) was added $(l)$.

\section{Cell Imaging}

HeLa cells and SKBR3 cells were obtained from the Korean Cell Line Bank (KCLB) and cultured in Dulbecco's modified Eagle's medium (DMEM, Welgene) supplemented with 10\% fetal bovine serum (FBS, Gibco) and 1\% penicillin-streptomycin (Gibco) at $37^{\circ} \mathrm{C}$ in a $5 \% \mathrm{CO}_{2}$ humidified atmosphere. Cells were seeded 48 hours before imaging on $18 \mathrm{~mm}$ round cover glasses cleaned previously with acetone, $1 \mathrm{M} \mathrm{KOH}$, and methanol.

The cells were briefly rinsed in phenol red-free DMEM for immunostaining. The cells were blocked with $1 \%$ BSA for 60 min at $37^{\circ} \mathrm{C}$. Then, EGFR antibody conjugated to Cy5 or AF647 was incubated with 3\% BSA for $15 \mathrm{~min}$ at room temperature. The cells were washed three times with phenol red-free DMEM. For live cell imaging, cells on glass were maintained at $37{ }^{\circ} \mathrm{C}$ supplied with $5 \% \mathrm{CO}_{2}$ in a live-cell chamber (Chamlide TCA, Live Cell Instrument, Republic of Korea) mounted on the microscope. Imaging was performed in phenol red-free DMEM unless otherwise noted. For fixed cell imaging, cells were fixed with ice-cold methanol $\left(-20^{\circ} \mathrm{C}\right)$ for $15 \mathrm{~min}$ and thoroughly rinsed with PBS 5 times before imaging. Imaging was performed in PBS buffer unless otherwise noted. An oxygen scavenging system (2.5 mM protocatechuic acid, 1x protocatechuic 3,4dioxygenase) and triplet state quencher Trolox $1 \mathrm{mM}$ (TX in ethanol, 200x) were added for single-molecule imaging conditions. For superresolution imaging (dSTORM), the oxygen scavenger system was supplemented with cysteamine (MEA) $1 \mathrm{mM}$ (live cell) or $50 \mathrm{mM}$ (fixed cell).

\section{Analysis of Fluorescence Images}

To count the number of fluorophores on either PEGylated glass or fixed cells, two methods have been used depending on the density of fluorophores. For the dyes, of which density is higher than the single-molecule level, the total fluorescence intensity of Cy5 or AF647 was measured by illumination with a $642 \mathrm{~nm}$ laser. The fluorescence intensity of a single dye was quantified under the same imaging conditions. A total of 200 image frames were acquired to sort fluorophores with a single photobleaching step for the calculation of the intensity and the background level. The median intensity was used to avoid outliers. Total fluorescence intensity was subtracted from the background level. The total number of dyes was obtained by the ratio of the total fluorescence intensity and the single-molecule intensity. The density of the fluorophore was adjusted to the 
same level for each experiment. The number of photoconverted fluorophores for each frame was obtained by counting the number of molecules. Only signals with a signal-to-noise ratio (SNR) over 4 were used.

When the density of fluorophore was low as the single-molecule level $\left(<2\right.$ molecule $\left./ \mu \mathrm{m}^{2}\right)$, each fluorescent spot of Cy5 was localized before the photoconversion by the $642 \mathrm{~nm}$ laser illumination. Then, the $532 \mathrm{~nm}$ laser was illuminated and the photoconverted products of the fluorophores were co-localized. The pre-converted dyes before the $642 \mathrm{~nm}$ laser illumination were excluded in calculating the conversion ratio (the number of converted dyes/the number of Cy5 dyes). In order to minimize the artifact due to the background noise (the false positives), we only counted the photoconverted molecules that co-localize with the positions of Cy5 with the threshold of 0.51 pixel. The threshold for co-localization was determined by imaging beads. The microsphere beads, sparsely distributed on the region of interest in the green and red excitation channel, were illuminated by both $642 \mathrm{~nm}$ and $532 \mathrm{~nm}$ lasers, and their locations were recorded for each detection channel. The center of the bead is localized by Gaussian fit, and the coordinates were used to calculate the rotational and translational differences between two channels. The transformation matrix was used to correct the differences. The average distance between the beads in each channel after the correction was 0.19 pixel with the standard deviation of 0.16 pixel. The upper limit of co-localization distance for $95 \%$ confidence was 0.51 pixel (= average value 0.19 pixel $+1.96 \times$ standard deviation 0.16 pixel). Thus, we set 0.51 pixel as the threshold for co-localization of $\mathrm{Cy} 5$ and pcCy5.

\section{Single-Particle Tracking}

Single-particle tracking was performed by a home-built algorithm based on the u-track program(2). The diffusion coefficient of each trajectory was calculated from the mean square displacement (MSD) with the twodimensional free diffusion model equation. Single molecules over SNR 3 were subjected to the tracking algorithm, and trajectories with only a duration longer than five frames were tracked and collected. Each time point was acquired in a stream of 200 frames with a $50 \mathrm{~ms}$ frame rate. The trajectory number in cell-only calculated trajectories diffusing on the lower part of the membrane were analyzed by excluding the trajectories on the edge of the cells diffusing in from the upper part of the membrane. The diffusion coefficient was calculated using trajectories longer than 10 frames with 3 time lags of their MSD. 


\section{Classification of Single-Particle Tracked Trajectory}

After tracking EGFR in live cells, trajectories over 10 frames were sorted into three different groups for further analysis. To minimize the effect of false positives in the trajectories, the MSD of each trajectory was calculated with a time lag of $150 \mathrm{~ms}$, and three consecutive MSDs were compared to the value $2 *$ localization error. If none of the three consecutive MSDs exceeded the value, the trajectory was sorted as immobile. For the rest of the trajectories, if there were three consecutive MSDs lower than a given value, it was considered a mix of mobile and immobile trajectories. If not, it was a mobile trajectory with no confined motion inside.

\section{References for Supplementary Information}

1. R. Roy, S. Hohng, T. Ha, A practical guide to single-molecule FRET. Nature Methods 5, 507-516 (2008).

2. K. Jaqaman et al., Robust single-particle tracking in live-cell time-lapse sequences. Nature Methods 5, 695-702 (2008). 


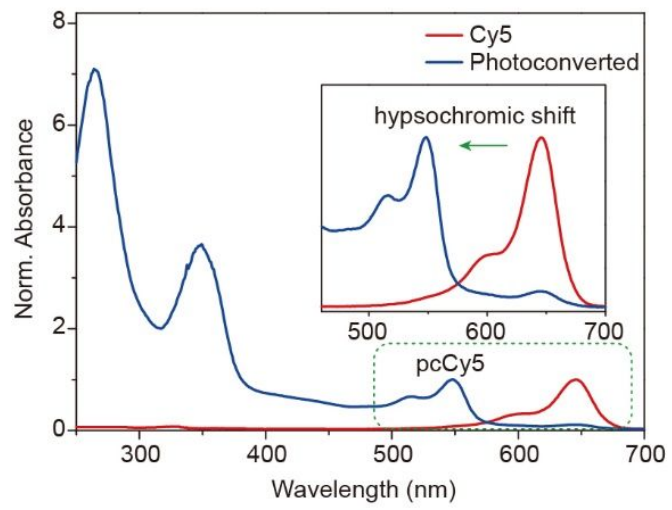

\section{Figure S1. Absorption spectra of Cy5 before and after photoconversion.}

Normalized absorption spectra of $\mathrm{Cy} 5$ before (red) and after (blue) photoconversion. The sample was irradiated for 8 hours by a $642 \mathrm{~nm}$ laser at a power of $300 \mathrm{~mW}$ with stirring. Absorption spectra were normalized according to the absorbance at $647 \mathrm{~nm}$ and $547 \mathrm{~nm}$ before and after photoconversion, respectively. The peaks at $265 \mathrm{~nm}$ and $350 \mathrm{~nm}$ correspond to the carbonyl products generated from photooxidation (Supplementary Figure 13) 

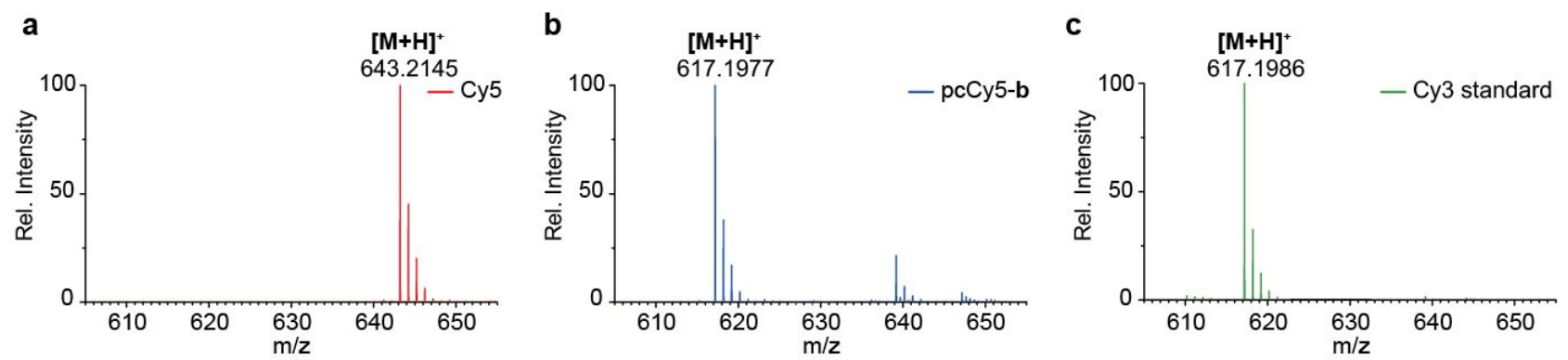

Figure S2. LC/HRMS spectra of Cy5 photoconversion.

Positive-mode LC/HRMS spectra of (a) Cy5, (b) pcCy5-b, and (c) Cy3 standard. The peak for $[\mathrm{M}+\mathrm{H}]^{+}$at $\mathrm{m} / \mathrm{z}$ 643.2145 corresponds to Cy5 before photoconversion. HPLC-purified pcCy5-b reveals a major peak for $[\mathrm{M}+\mathrm{H}]^{+}$at $\mathrm{m} / \mathrm{z}$ 617.1977. The mass peak shifts of -26.0168 are identical to the mass $\mathrm{C}_{2} \mathrm{H}_{2}(26.02)$, i.e., the difference between the polymethine chain lengths of $\mathrm{Cy} 5$ and $\mathrm{Cy} 3$. The Cy3 standard reveals a major peak for $[\mathrm{M}+\mathrm{H}]^{+}$at $\mathrm{m} / \mathrm{z}$ 617.1986, identical to that of pcCy5-b. 
a



b

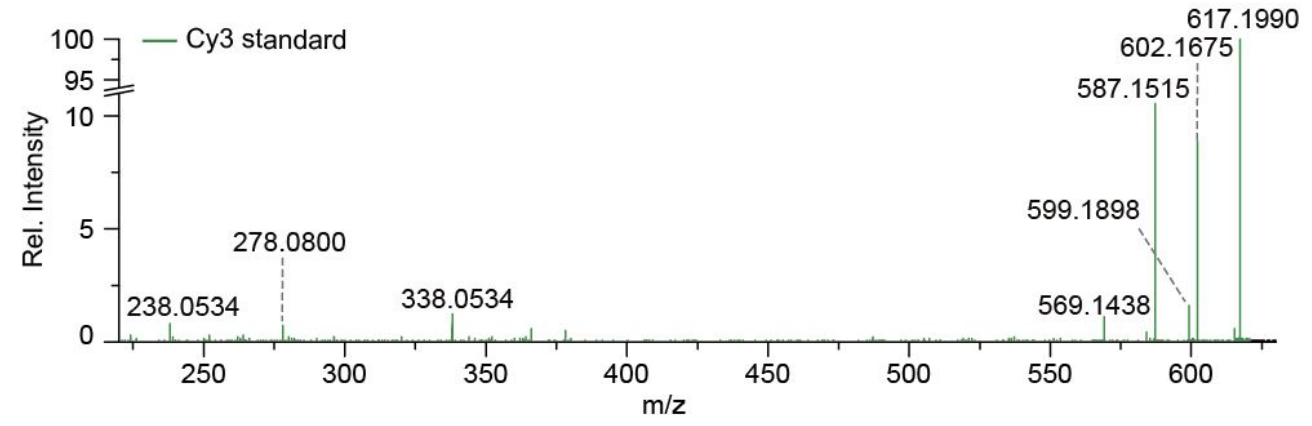

C

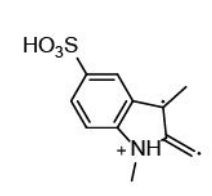

$\mathrm{C}_{11} \mathrm{H}_{12} \mathrm{NO}_{3} \mathrm{~S}^{2++}$

Exact Mass: 238.05

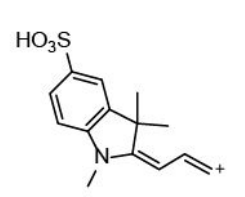

$\mathrm{C}_{14} \mathrm{H}_{16} \mathrm{NO}_{3} \mathrm{~S}^{+}$ Exact Mass: 278.08



$\mathrm{C}_{16} \mathrm{H}_{20} \mathrm{NO}_{5} \mathrm{~S}^{2++}$

Exact Mass: 338.11

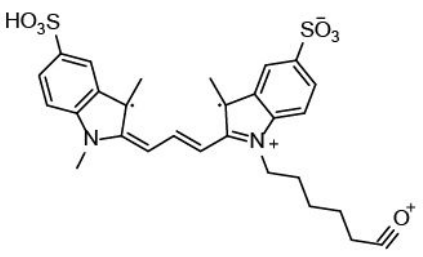

$\mathrm{C}_{28} \mathrm{H}_{29} \mathrm{~N}_{2} \mathrm{O}_{7} \mathrm{~S}_{2}{ }^{2+}$

Exact Mass: 569.14



$\mathrm{C}_{28} \mathrm{H}_{31} \mathrm{~N}_{2} \mathrm{O}_{8} \mathrm{~S}_{2}{ }^{2++}$

Exact Mass: 587.15

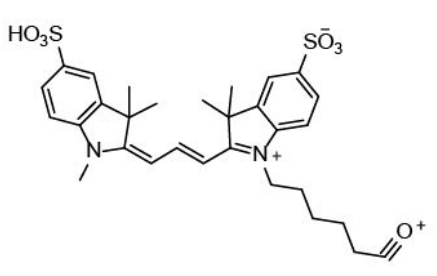

$\mathrm{C}_{30} \mathrm{H}_{35} \mathrm{~N}_{2} \mathrm{O}_{7} \mathrm{~S}_{2}{ }^{+}$

Exact Mass: 599.19

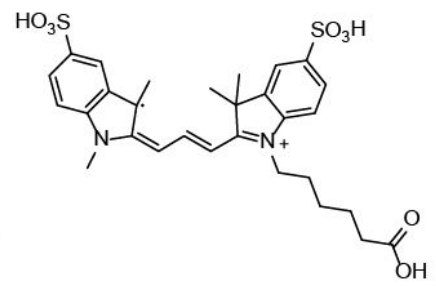

$\mathrm{C}_{29} \mathrm{H}_{34} \mathrm{~N}_{2} \mathrm{O}_{8} \mathrm{~S}_{2}{ }^{2+}$

Exact Mass: 602.18

\section{Figure S3. MS/MS spectra of pcCy5-b and Cy3 standard.}

Positive-mode high-resolution MS/MS spectra of (a) pcCy5-b and (b) Cy3 standard. The fragmentation patterns of pcCy5-b and $\mathrm{Cy} 3$ standard coincide. (c) Fragment assignments. The possible structure, chemical formula, and exact mass value are shown for each major peak in the MS/MS spectra. 


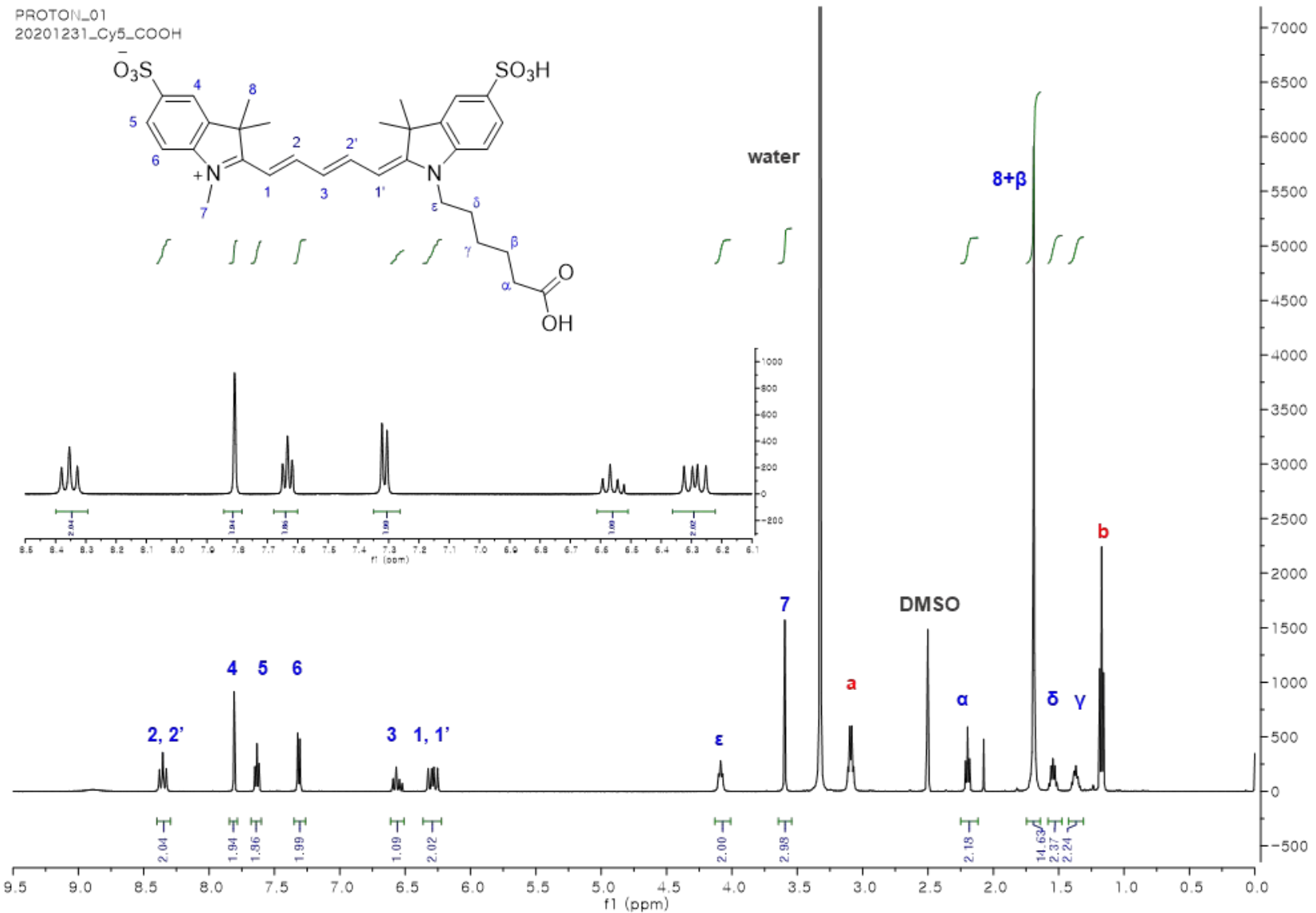

Figure S4. ${ }^{1} \mathrm{H}$ NMR spectrum of Cy5.

The Cy5 standard was subjected to HPLC separation conditions ( 50 mM TEAA, followed by $0.1 \%$ TFA) before NMR analysis. Peaks a and $b$ (red) correspond to TEAA. The peak assignments are as follows: ${ }^{1} \mathrm{H}$ NMR (499 MHz, DMSO-d $\left.{ }_{6}\right) \delta 8.35(\mathrm{t}, J=13.1 \mathrm{~Hz}, 2 \mathrm{H}), 7.81(\mathrm{~s}, 2 \mathrm{H}), 7.63(\mathrm{t}, J=7.8 \mathrm{~Hz}, 2 \mathrm{H}), 7.31(\mathrm{~d}, J=8.3 \mathrm{~Hz}, 2 \mathrm{H})$, $6.56(\mathrm{dd}, J=23.8,11.4 \mathrm{~Hz}, 1 \mathrm{H}), 6.29(\mathrm{dd}, J=22.1,13.9 \mathrm{~Hz}, 2 \mathrm{H}), 4.09$ (t, $J=7.1 \mathrm{~Hz}, 2 \mathrm{H}), 3.60$ (s, 3H), 2.20 (t, $J=7.2 \mathrm{~Hz}, 2 \mathrm{H}), 1.69(\mathrm{~s}, 14 \mathrm{H}), 1.58-1.48(\mathrm{~m}, 2 \mathrm{H}), 1.42-1.31(\mathrm{~m}, 2 \mathrm{H})$. 




Figure S5. ${ }^{1} \mathrm{H}$ NMR spectrum of pcCy5-b.

The peak assignments are as follows: ${ }^{1} \mathrm{H}$ NMR (499 MHz, DMSO-d $\left.{ }_{6}\right) \delta 8.35(\mathrm{t}, J=13.5 \mathrm{~Hz}, 1 \mathrm{H}), 7.79(\mathrm{~s}, 2 \mathrm{H})$, $7.67(\mathrm{t}, J=8.1 \mathrm{~Hz}, 2 \mathrm{H}), 7.39(\mathrm{dd}, J=8.2,2.5 \mathrm{~Hz}, 2 \mathrm{H}), 6.48(\mathrm{dd}, J=13.3,9.1 \mathrm{~Hz}, 2 \mathrm{H}), 4.11(\mathrm{t}, J=7.0 \mathrm{~Hz}, 2 \mathrm{H})$, $3.65(\mathrm{~s}, 3 \mathrm{H}), 2.22(\mathrm{t}, J=7.1 \mathrm{~Hz}, 2 \mathrm{H}), 1.81-1.64(\mathrm{~m}, 14 \mathrm{H}), 1.63-1.52(\mathrm{~m}, 2 \mathrm{H}), 1.45-1.35(\mathrm{~m}, 2 \mathrm{H})$. Peaks a and $\mathrm{b}$ (red) correspond to TEAA. 


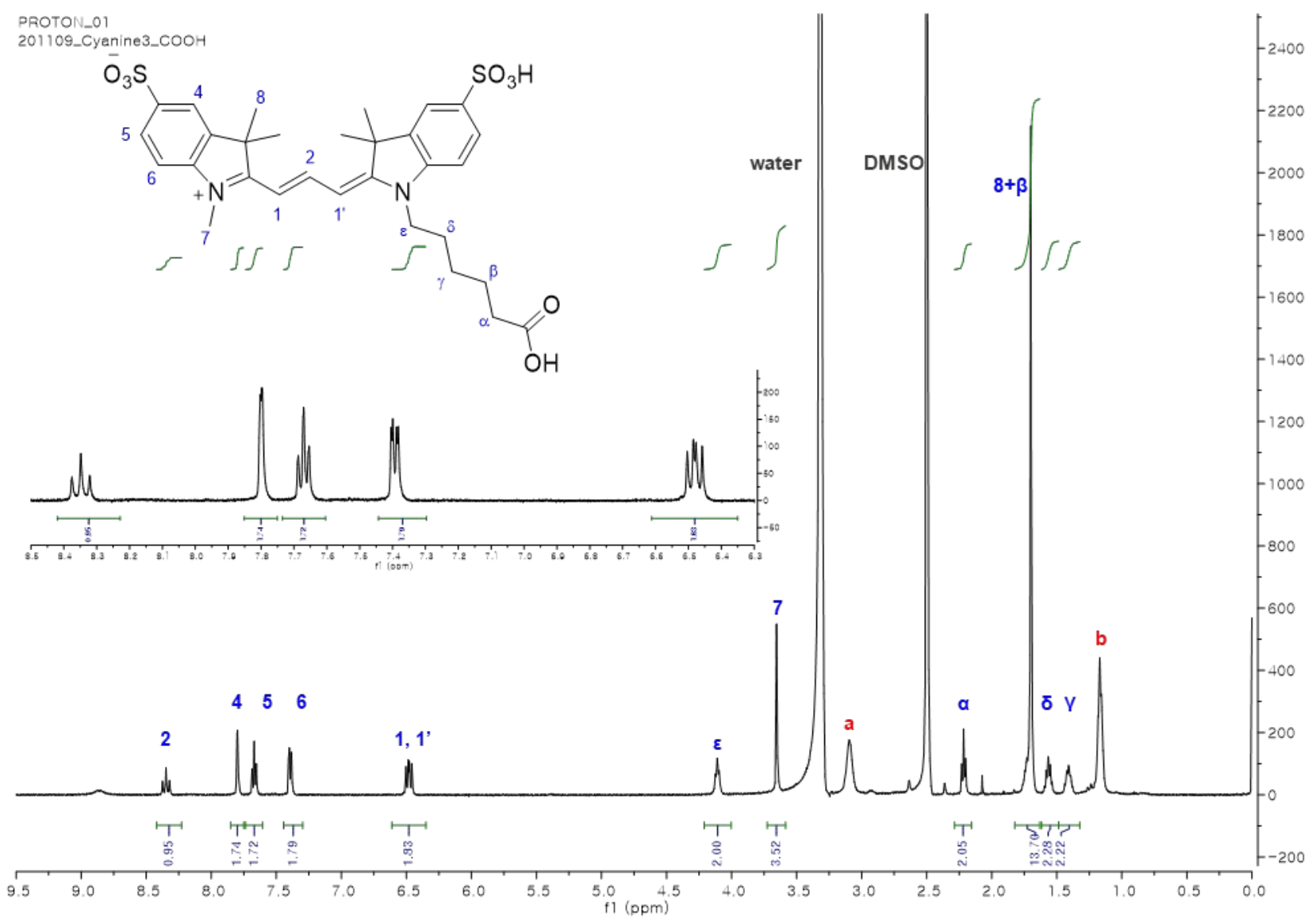

Figure S6. ${ }^{1} \mathrm{H}$ NMR spectrum of $\mathrm{Cy} 3$ standard.

The Cy3 standard was subjected to the HPLC separation conditions (50 mM TEAA, followed by 0.1\% TFA) identical to those applied to pcCy5-b before NMR analysis. The peak assignments are as follows: ${ }^{1} \mathrm{H}$ NMR (499 MHz, DMSO-d $\left.{ }_{6}\right) \delta 8.35(\mathrm{t}, J=13.5 \mathrm{~Hz}, 1 \mathrm{H}), 7.80(\mathrm{~s}, 2 \mathrm{H}), 7.67(\mathrm{t}, J=8.2 \mathrm{~Hz}, 2 \mathrm{H}), 7.39$ (dd, $J=8.3,2.6 \mathrm{~Hz}$, 2H), $6.48(\mathrm{dd}, J=13.3,9.3 \mathrm{~Hz}, 2 \mathrm{H}), 4.11$ (t, $J=7.1 \mathrm{~Hz}, 2 \mathrm{H}), 3.65$ (s, 3H), 2.22 (t, $J=7.2 \mathrm{~Hz}, 2 \mathrm{H}), 1.82-1.63$ $(\mathrm{m}, 14 \mathrm{H}), 1.62-1.48(\mathrm{~m}, 2 \mathrm{H}), 1.48-1.32(\mathrm{~m}, 2 \mathrm{H})$. Peaks a and $\mathrm{b}$ (red) correspond to TEAA. 
a



Cyanine5.5

b

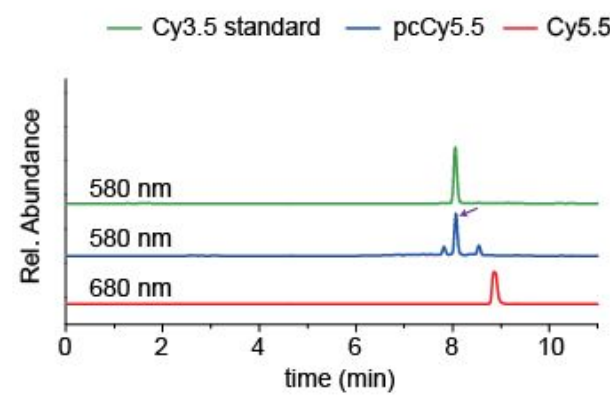

d

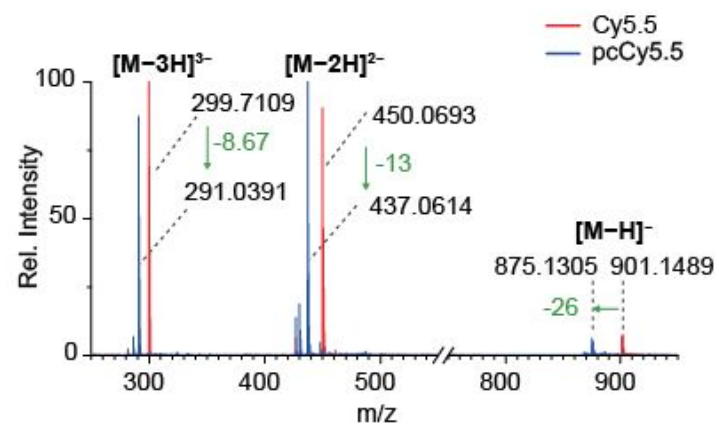

C

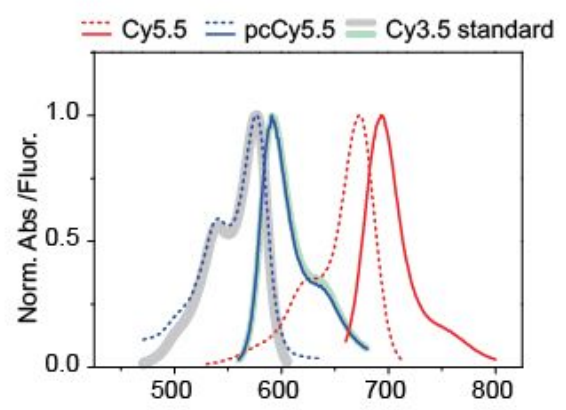

Figure S7. Photoconversion of Cy5.5.

(a) Schematic of the photoconversion of $\mathrm{Cy} 5.5$ to $\mathrm{Cy} 3.5$, i.e., pcCy5.5, upon irradiation with a red laser. (b) High-performance liquid chromatograms of Cy5.5 before (red) and after photoconversion (blue) and of Cy3.5 standard (green). UV-Vis detection at $680 \mathrm{~nm}$ and $580 \mathrm{~nm}$ was recorded as denoted. The sample in distilled water was photoconverted by 8 hours of irradiation with a $642 \mathrm{~nm}$ laser at a power of $300 \mathrm{~mW}$ under stirring. The photoreaction solution exhibits one major peak and two minor peaks at relative times of $8.1 \mathrm{~min}, 7.8 \mathrm{~min}$, and $8.4 \mathrm{~min}$, shifted from that of Cy5.5 at $8.9 \mathrm{~min}$. The purple arrow indicates the major peak. (c) Normalized absorption (dotted line) and emission (solid line) spectra of Cy5.5 (red), isolated major peaks of pcCy5.5 (blue), and Cy3.5 standard (gray: absorption, green: emission). The spectroscopic properties of pcCy5.5 are identical to those of Cy3.5 standard. (d) Negative-mode LC/HRMS spectra of 
Cy5.5 (red) and HPLC-purified pcCy5.5 (blue). The mass peak shifts are observed to be $-26.0184,-13.0079$, and -8.6718 for $[\mathrm{M}-\mathrm{H}]^{-},[\mathrm{M}-2 \mathrm{H}]^{2-}$, and $[\mathrm{M}-3 \mathrm{H}]^{3-}$, respectively, which are identical to the mass $\mathrm{of}_{2} \mathrm{H}_{2}$. (e) Negative-mode LC/HRMS spectrum of Cy3.5 standard. The spectrum reveals major peaks for $[\mathrm{M}-\mathrm{H}]^{-}$, $[\mathrm{M}-2 \mathrm{H}]^{2-}$, and $[\mathrm{M}-3 \mathrm{H}]^{3-}$, with a mass value identical to that of pcCy5.5. 
a



C



b

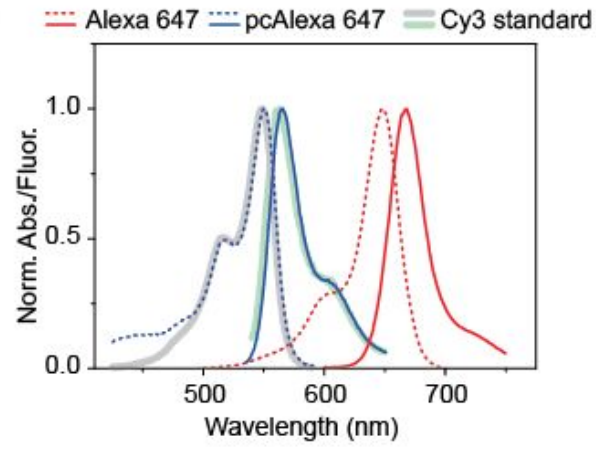

\section{Figure S8. Photoconversion of AF647.}

(a) High-performance liquid chromatogram of AF647 before (red) and after photoconversion (blue). UVVis detection at $650 \mathrm{~nm}$ and $547 \mathrm{~nm}$ was recorded as denoted. The sample in distilled water was photoconverted by 8 hours of irradiation with a $642 \mathrm{~nm}$ laser at a power of $300 \mathrm{~mW}$ under stirring. The photoreaction solution exhibits one major peak at a relative time of $6.4 \mathrm{~min}$, shifted from that of AF647 at 7.3 min. (b) Normalized absorption (dotted line) and emission (solid line) spectra of AF647 (red), isolated peaks of pcAF647 (blue), and Cy3 (gray: absorption, green: emission). In the absence of a commercial standard for pcAF647, the absorption and emission spectra were compared to those of Cy3. The only difference between the pcAF647 and Cy3 structures is the number of sulfonate groups. (c) Negative-mode LC/HRMS spectra of AF647 (red) and HPLC-purified pcAF647 (blue). The mass peak shifts are observed to be $-26.0145,-13.0071$, and -8.6708 for $[\mathrm{M}-\mathrm{H}]^{-},[\mathrm{M}-2 \mathrm{H}]^{2-}$, and $[\mathrm{M}-3 \mathrm{H}]^{3-}$, respectively, which are identical to the mass of $\mathrm{C}_{2} \mathrm{H}_{2}$. 
a
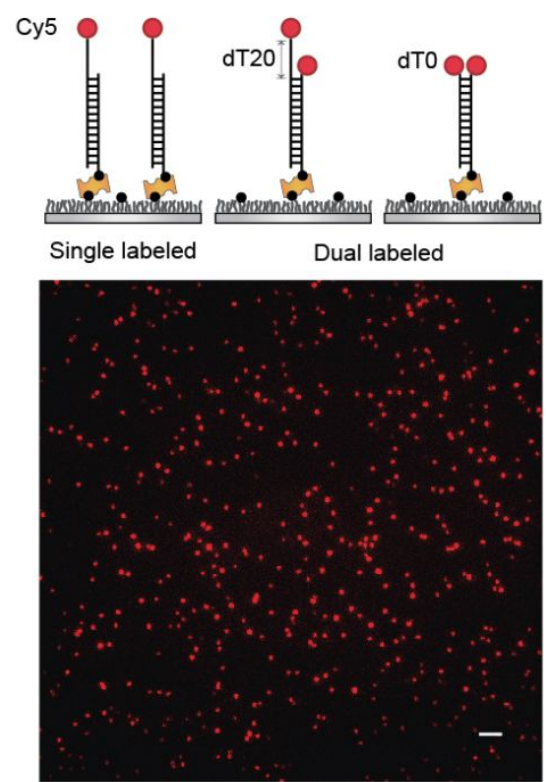

b

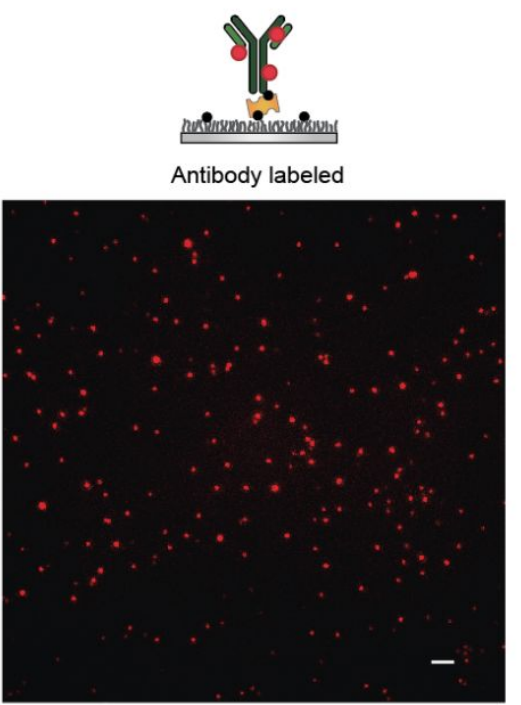

Figure S9. Quantitative measurements of the photoconversion ratio of $\mathrm{Cy5}$ at the single-molecule level.

(a) Representative fluorescent image of dT0 at the single-molecule level before photoconversion. Scale bar, 2 $\mu \mathrm{m}$. (b) Representative fluorescent image of Cy5-labeled antibody (DOL 4) at the single-molecule level. Scale bar, $2 \mu \mathrm{m}$. 
a

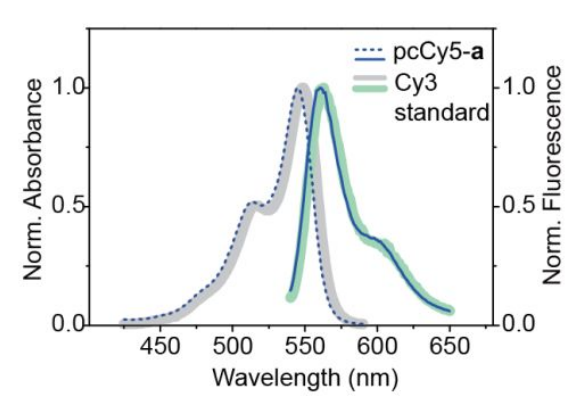

d

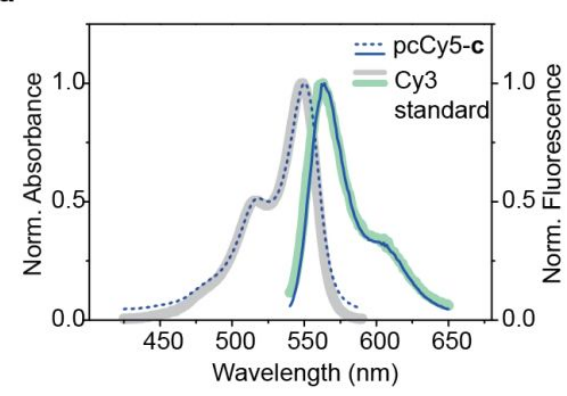

b

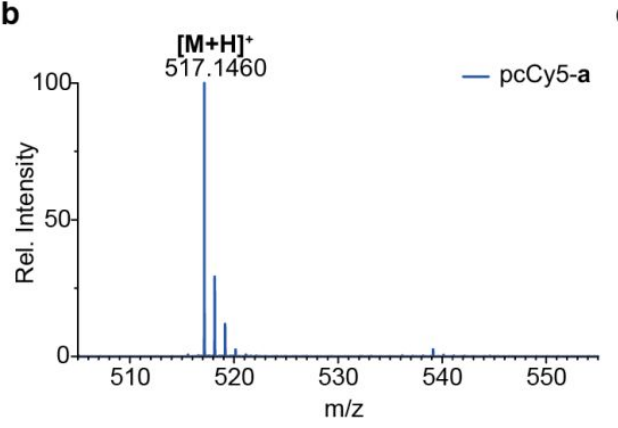

e



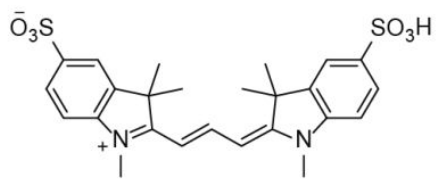

pcCy5-a

Figure S10. Formation of symmetric compounds of pcCy5.

Minor peaks a and $\mathbf{c}$ in the HPLC chromatogram of the photoconverted solution of Cy5 in Fig. 1d were characterized by obtaining spectral properties and HRMS spectra. (a-c) peak a, pcCy5-a. (d-f) peak c, pcCy5-c. (a), (d) Normalized absorption and emission spectra of pcCy5-a and pcCy5-c (blue) and Cy3 standard (gray: absorption green: emission). The spectroscopic properties of pcCy5-a and pcCy5-c match those of Cy3 standard. (b), (e) Positive-mode HRMS spectra of pcCy5-a and pcCy5-c. The shifts in peaks compared to pcCy5-b were -100.0517 and +100.0512 , respectively, which correspond to the difference in mass between $\mathrm{CH}_{3}(15.02)$ and $\left(\mathrm{CH}_{2}\right)_{5} \mathrm{COOH}$ (115.07), and the aliphatic tails appended to the indole ring. We inferred that symmetric compounds of $\mathrm{Cy} 3$ (c) and (f) were formed by the photoreaction, supported by the relative retention time (Fig. 1d) and their MS/MS spectra. (Supplementary Fig. 11-12) (c), (f) Chemical structures of pcCy5-a and pcCy5-c. 
a

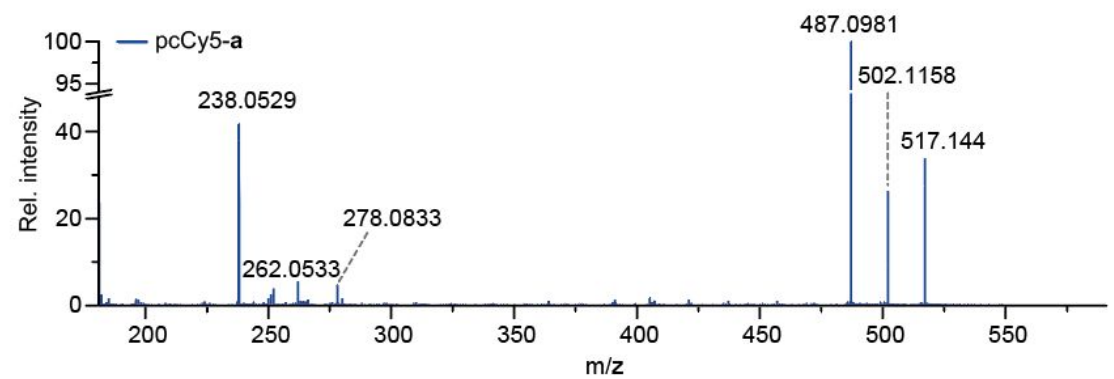

b



$\mathrm{C}_{11} \mathrm{H}_{12} \mathrm{NO}_{3} \mathrm{~S}^{2++}$

Exact Mass: 238.05

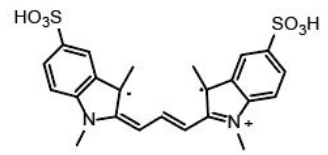

$\mathrm{C}_{23} \mathrm{H}_{23} \mathrm{~N}_{2} \mathrm{O}_{6} \mathrm{~S}_{2}{ }^{2++}$

Exact Mass: 487.10

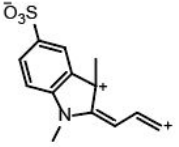

$\mathrm{C}_{13} \mathrm{H}_{12} \mathrm{NO}_{3} \mathrm{~S}^{+}$

Exact Mass: 262.05



$\mathrm{C}_{24} \mathrm{H}_{26} \mathrm{~N}_{2} \mathrm{O}_{6} \mathrm{~S}_{2}{ }^{+}$

Exact Mass: 502.12

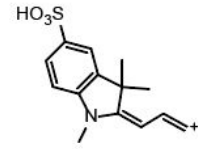

$\mathrm{C}_{14} \mathrm{H}_{16} \mathrm{NO}_{3} \mathrm{~S}^{+}$

Exact Mass: 278.08

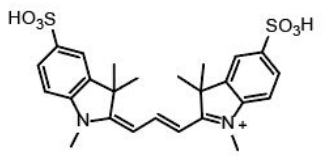

$\mathrm{C}_{25} \mathrm{H}_{20} \mathrm{~N}_{2} \mathrm{O}_{6} \mathrm{~S}_{2}{ }^{++}$

Exact Mass: 517.15

\section{Figure S11. MS/MS spectrum of pcCy5-a.}

(a) Positive-mode high-resolution MS/MS spectra of pcCy5-a. (b) Fragment assignments. The possible structure, chemical formula, and exact mass value are shown for each major peak in the MS/MS spectra. 
a

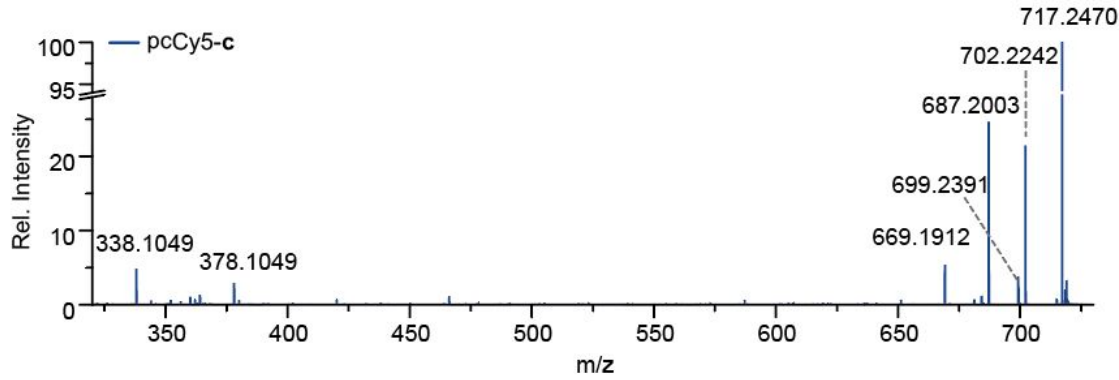

b


Figure S12. MS/MS spectrum of pcCy5-c.

(a) Positive-mode high-resolution MS/MS spectra of pcCy5-c. (b) Fragment assignments. The possible structure, chemical formula, and exact mass value are shown for each major peak in the MS/MS spectra. 
a



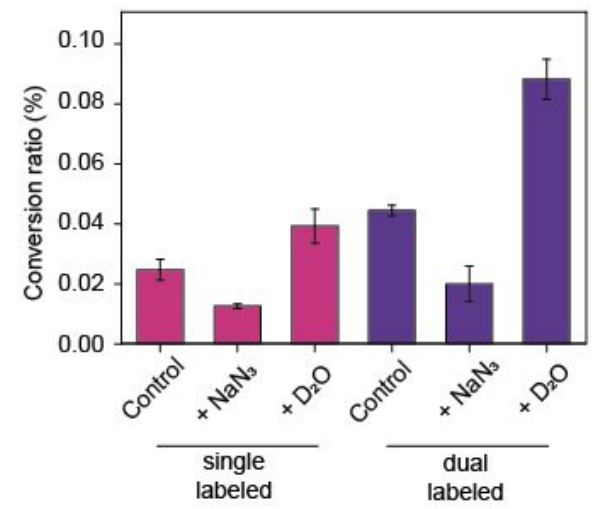

Figure S13. Photoconversion of $\mathrm{Cy} 5$ is inhibited in singlet oxygen-depleted conditions.

(a) Time traces of the number of pcCy5 molecules per $\mu \mathrm{m}^{2}$ in single-molecule imaging under various oxygendepleted conditions. The lines are linear guidelines for clarity. The control was imaged in Tris buffer (pH 7.5) without $642 \mathrm{~nm}$ illumination for each condition. The gray line is a representative control for the GOC condition. The error bars indicate the mean \pm s.e.m.; $\mathrm{n}=15$ measurements from two independent experiments.

(b) Photoconversion ratios of Cy5 singly-labeled DNA and dT0 (dual labeled) in the presence of $33 \mathrm{mM} \mathrm{NaN}_{3}$ or $45 \% \mathrm{D}_{2} \mathrm{O}$. The conversion ratio is calculated by dividing the number of Cy3, co-localized with the Cy5 positions after $45 \mathrm{sec}$ illumination of the $642 \mathrm{~nm}$ laser at a power of $1 \mathrm{~mW}$, by the number of initial Cy5 molecules. Approximately 50,000 to 70,000 Cy5 molecules were imaged for each sample, and the error bars were obtained from three independent experiments. 
a

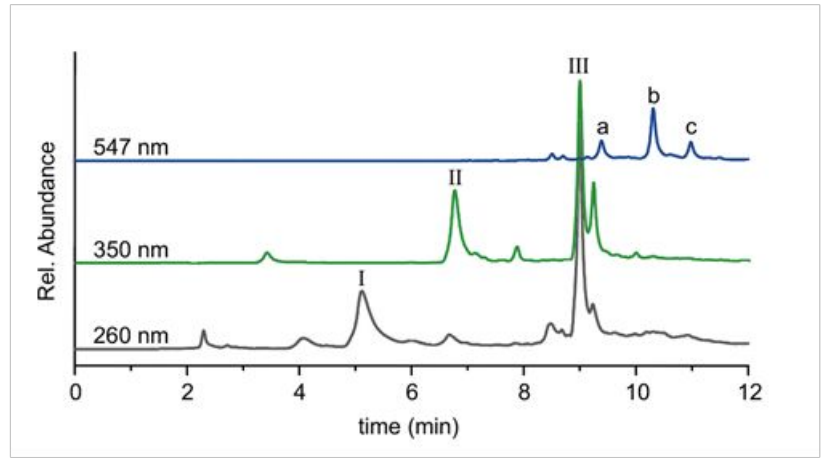

b

\begin{tabular}{cccc}
\hline Peak & \multicolumn{2}{c}{ Mass to Charge Ratio $(\mathbf{m} / \mathbf{z})$} & \multirow{2}{*}{$\begin{array}{l}\text { Chemical } \\
\text { Formula }\end{array}$} \\
\cline { 2 - 3 } & Observed & Theoretical & \\
\hline Ia & 258.0639 & 258.0638 & $\mathrm{C}_{11} \mathrm{H}_{14} \mathrm{NO}_{4} \mathrm{~S}^{+}$ \\
IIa & 282.0791 & 282.0795 & $\mathrm{C}_{13} \mathrm{H}_{16} \mathrm{NO}_{4} \mathrm{~S}^{+}$ \\
IIb & 254.0846 & 254.0845 & $\mathrm{C}_{12} \mathrm{H}_{16} \mathrm{NO}_{3} \mathrm{~S}^{+}$ \\
IIc & 354.1363 & 354.1340 & $\mathrm{C}_{17} \mathrm{H}_{24} \mathrm{NO}_{5} \mathrm{~S}^{+}$ \\
IIIa & 356.1156 & 356.1168 & $\mathrm{C}_{16} \mathrm{H}_{22} \mathrm{NO}_{6} \mathrm{~S}^{+}$ \\
IIIb & 382.1321 & 382.1319 & $\mathrm{C}_{18} \mathrm{H}_{24} \mathrm{NO}_{6} \mathrm{~S}^{+}$ \\
IIIc & 354.1374 & 354.1340 & $\mathrm{C}_{17} \mathrm{H}_{24} \mathrm{NO}_{5} \mathrm{~S}^{+}$ \\
\hline
\end{tabular}

C
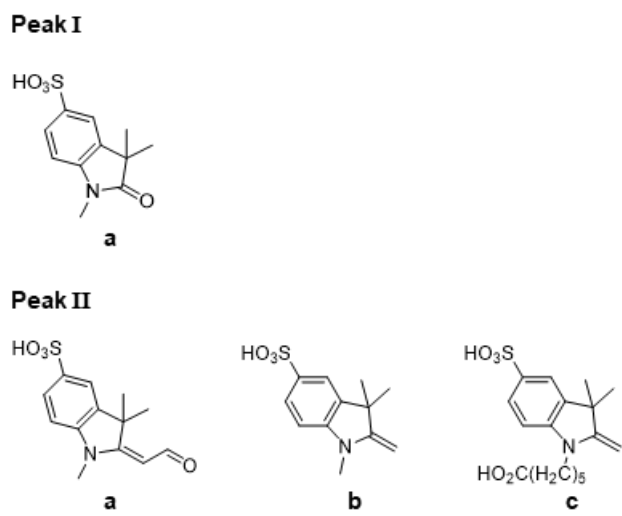

Peak III


b

c

\section{Figure S14. Identification of the photoreaction products of Cy5.}

(a) HPLC chromatogram of photoconverted Cy5. Three major peaks (I, II and III) with absorption at $260 \mathrm{~nm}$ and $350 \mathrm{~nm}$ were observed. The carbonyl products formed from the photolysis of cyanine dyes show absorption at $260 \mathrm{~nm}$ and $350 \mathrm{~nm}$ (Figure S1). Three major peaks were isolated by HPLC purification. Each peak was further analyzed by LC/HRMS. (b) Positive-mode LC/HRMS analysis of peaks I, II and III. The mass peaks observed and calculated for $[\mathrm{M}+\mathrm{H}]^{+}$are denoted in the table. (c) Possible structures of the chemical compounds in each peak. Carbonyl products absorbing at $260 \mathrm{~nm}$ (Ia, IIIa) and $350 \mathrm{~nm}$ (IIa, IIIb) were observed. Fischer bases (IIb, IIc and IIIc) are also observed in peaks II and III. Peaks IIc and IIIc have been tentatively assigned to be the same Fischer's base. It is possible that the observed $\mathrm{m} / \mathrm{z}$ is a signal from fragmentation rather than a molecular ion, $\mathrm{M}^{+}$. 




\section{Figure S15. Intermediates of photoconversion of Cy5}

(a) Schematics of experiments for the reaction of isolated peak II in Figure S14a. Fluorescence spectra excited at $525 \mathrm{~nm}$ before and after the reaction. The fluorescence intensity at $561 \mathrm{~nm}$ increased by 20 -fold. (b) The projected reaction of the intermediates contained in the HPLC eluate peak II. Although the aldehyde with a carboxypentyl group $\left(\mathrm{R}=\left(\mathrm{CH}_{2}\right)_{5} \mathrm{CO}_{2} \mathrm{H}\right)$ was not detected in HRMS analysis (Figure $\left.\mathrm{S} 14\right)$, the symmetric Cy3 c $\left(\mathrm{R}=\mathrm{R}^{\prime}=\right.$ carboxypentyl) was formed as a minor product. (c) Chromatogram (detected at $\left.560 \mathrm{~nm}\right)$ after the reaction at $60^{\circ} \mathrm{C}$ for $24 \mathrm{~h}$. Each peak is assigned as denoted. Peaks A, B and C correspond to pcCy5-a, pcCy5-b, and pcCy5-c, respectively. 
a trans-Splicing pathway

1) Photooxidative cleavage
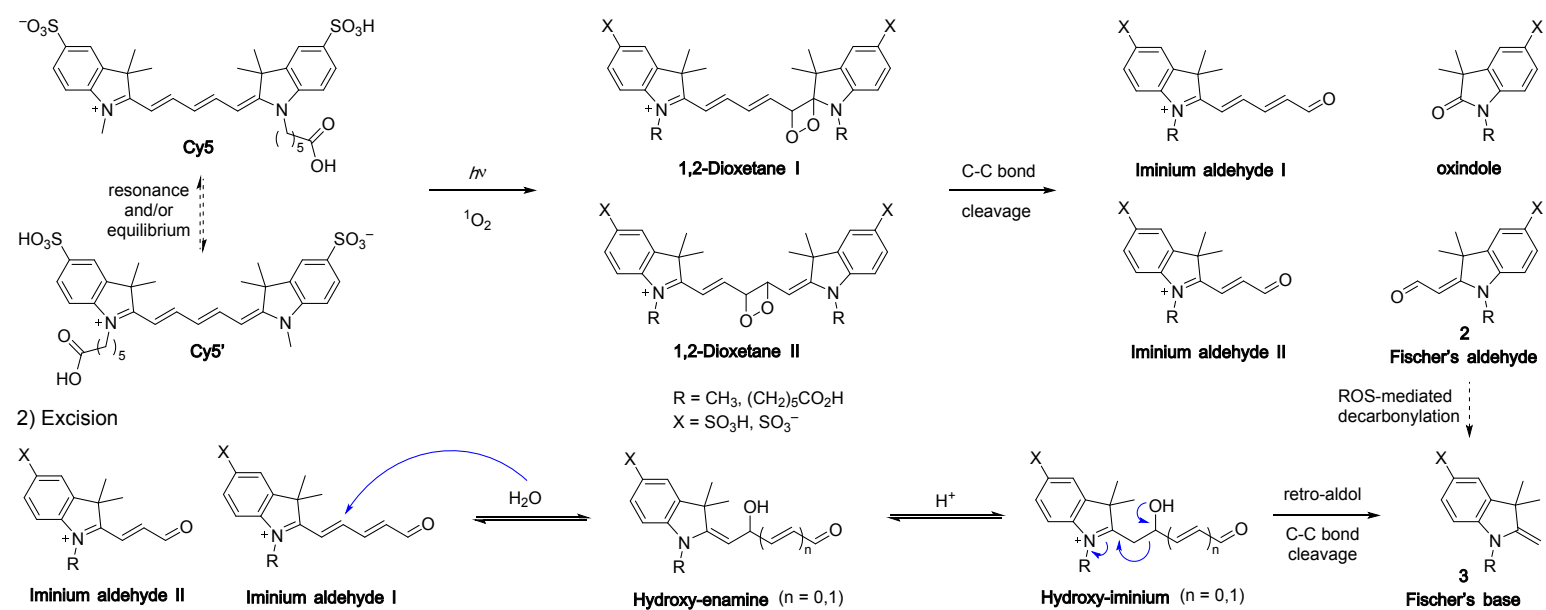

$\mathrm{R}=\mathrm{CH}_{3},\left(\mathrm{CH}_{2}\right)_{5} \mathrm{CO}_{2} \mathrm{H}$ $\mathrm{X}=\mathrm{SO}_{3} \mathrm{H}, \mathrm{SO}_{3}^{-}$
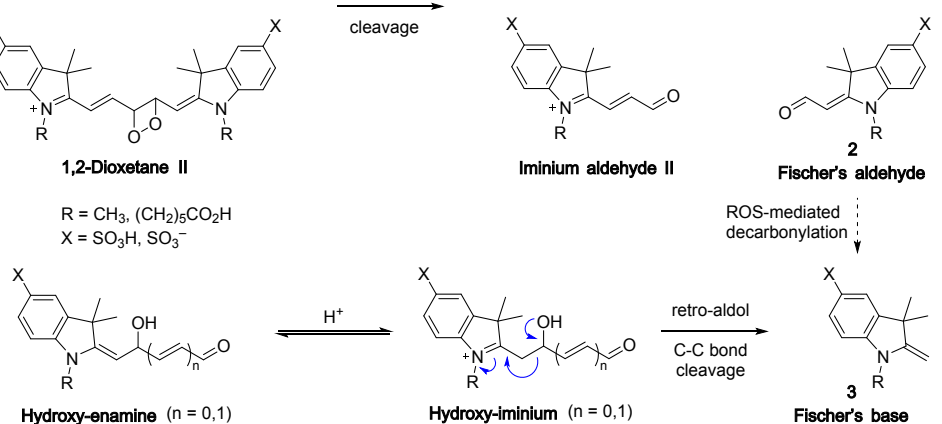

Hydroxy-enamine $(n=0,1)$

Hydroxy-iminium $(n=0,1)$

3) Reconstitution
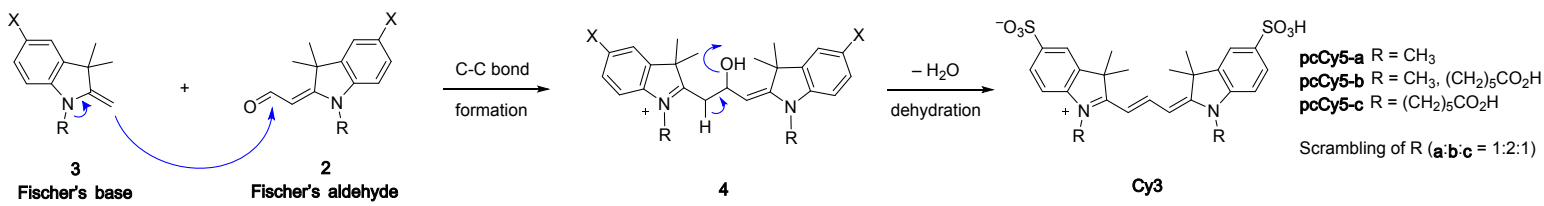

b cis-Splicing pathway

Intramolecular cut-and-sew

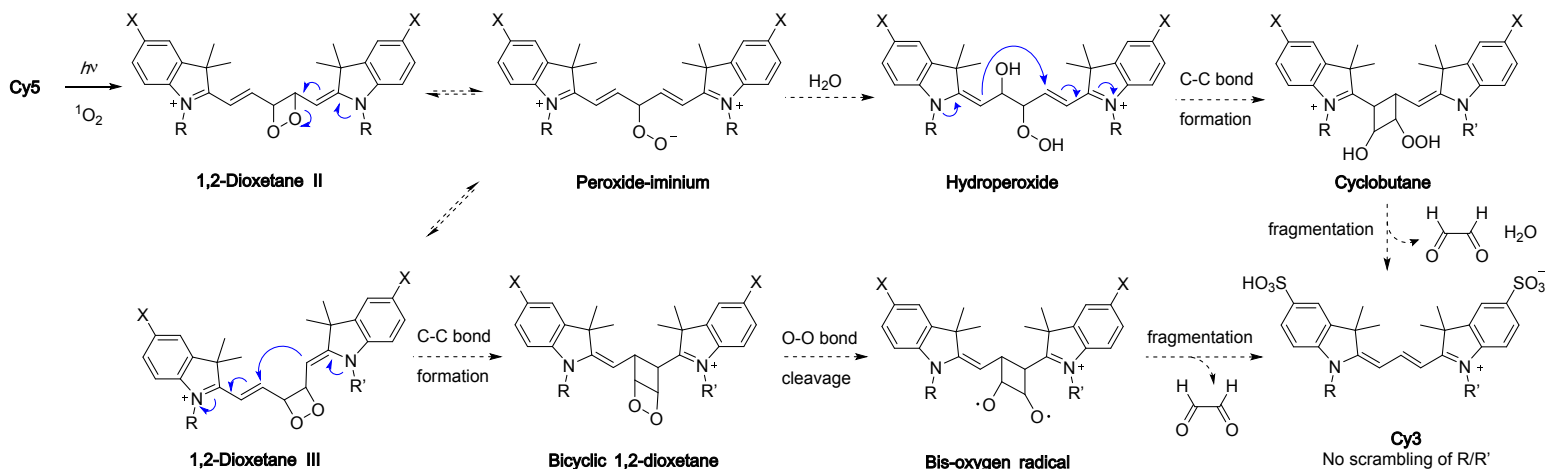

\section{Figure S16. Mechanistic pathways for the photoconversion of $\mathrm{Cy} 5$ to $\mathrm{Cy3}$}

(a) A trans-splicing pathway involving three stages. In the photooxidative cleavage stage, the C2'-C3' and C1'$\mathrm{C} 2$ alkenes react with singlet oxygen to generate 1,2-dioxetanes, which undergo $\mathrm{C}-\mathrm{C}$ bond cleavage to give iminium aldehydes, Fischer's aldehyde 2, and oxindole. In the excision stage, iminium aldehydes, no longer push-pull polyenes, are susceptible to water addition and may produce hydroxy-enamines which upon protonation are poised for retro-aldol-type C-C bond cleavage to form Fischer's base 3. In the final 
reconstitution stage, Fischer's base $\mathbf{3}$ and aldehyde $\mathbf{2}$ undergo intermolecular addition and condensation to form $\mathrm{Cy} 3$.

(b) A cis-splicing pathway involving intramolecular C-C bond formation and cleavage processes. The photoconversion of Cy5 would produce Cy3 without scrambling R and R' groups, i.e., the resulting Cy3 should contain $N$-methyl and $N^{\prime}$-carboxyalkyl groups. The isolation of pcCy5-a, pcCy5-b, and pcCy5-c in a 1:2:1 ratio lends supports to the trans-splicing mechanism for the $\mathrm{Cy} 5$ to $\mathrm{Cy} 3$ photoconversion. 
a
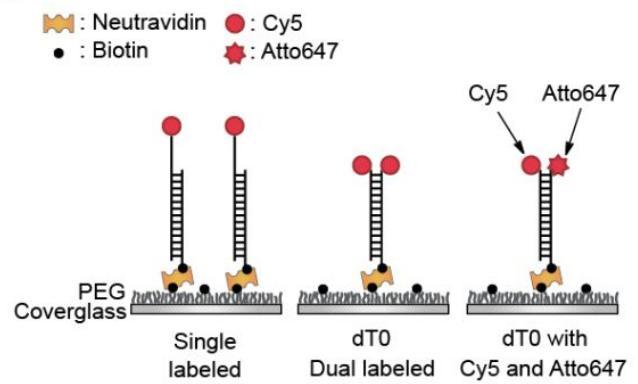

C

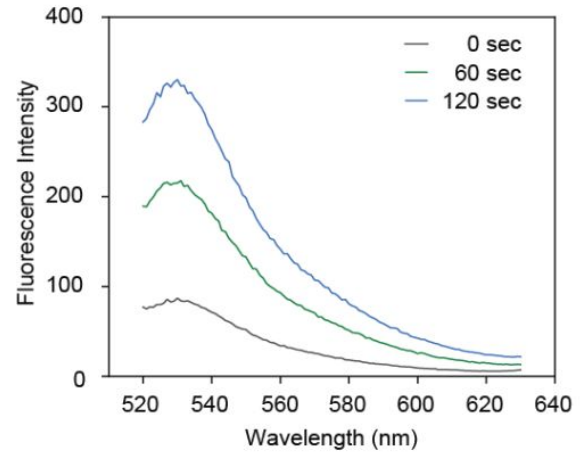



d

e


Figure S17. The effect of singlet oxygen on the photoconversion ratio of dT0 labeled with Cy5 and Atto647.

(a) A schematic illustration of the methodology used for visualizing the photoconversion of Cy5 to Cy3 using dT0 labeled with Cy5 and Atto647. The left two panels show singly- or dual-labeled dsDNA (dT0) with Cy5 dyes (the same images as in Figure 2a for the purpose of comparison). The right panel shows dT0 labeled with Cy5 and Atto647. Note that one of Cy5 was replaced with Atto647 in this case.

(b) Photoconversion ratios of $\mathrm{Cy} 5$ for the samples shown in (a). The photoconversion ratios of Cy5 singlylabeled DNA and dT0 in Figure 2c were re-presented here for the purpose of comparison. The photoconversion ratio of Atto647 alone was not observed (gray bar). dT0 labeled with Cy5 and Atto647 (brown bar) showed nearly the same photoconversion ratio per Cy5 molecule as that of Cy5 singly-labeled DNA. The photoconversion ratio was calculated by dividing the number of photoconverted Cy3 molecules, co-localized with the Cy5 (Atto647 for Atto647 sample) positions after $45 \mathrm{sec}$ illumination of the $642 \mathrm{~nm}$ laser at a power of $1 \mathrm{~mW}$, by the number of detected Cy5 dyes (Atto647 dyes for Atto647 sample). Approximately 50,000 to 110,000 Cy5 molecules (Atto647 molecules for Atto647 sample) were imaged for each sample. 
(c) Fluorescence intensity of Singlet Oxygen Sensor Green (SOSG, Thermo Scientific, USA) upon $642 \mathrm{~nm}$ laser illumination with $400 \mathrm{~mW}$ on Atto647 for the fixed time. The mixture of $10 \mu \mathrm{M}$ Atto647 and $2 \mu \mathrm{M}$ SOSG was prepared in $100 \mu \mathrm{L}$ of $100 \mathrm{mM}$ Tris-acetate $(\mathrm{pH}$ 7.5) buffer. The emission spectra of SOSG were recorded for a range of $520 \mathrm{~nm}$ to $630 \mathrm{~nm}$ using $504 \mathrm{~nm}$ excitation.

(d) Normalized fluorescence intensities of SOSG for Atto647 and Cy5 excitation, respectively. The increase of SOSG fluorescence intensity indicates the generation of singlet oxygen. The intensity was normalized using the intensity measured for $120 \mathrm{sec}$ illumination of the Cy5 sample. The dye concentration was 7-9 $\mu \mathrm{M}$ and the difference in the dye concentration between Atto647 and Cy5 was considered in the calculation. The error bars indicate the mean \pm s.e.m. from three independent experiments. Atto647 generated singlet oxygen approximately five times more than Cy5.

(e) The decay of maximum absorption in the absorption spectra of Atto647 and Cy5, respectively, as the duration of $642 \mathrm{~nm}$ illumination increases. The error bars indicate the mean \pm s.e.m. from three independent experiments. 


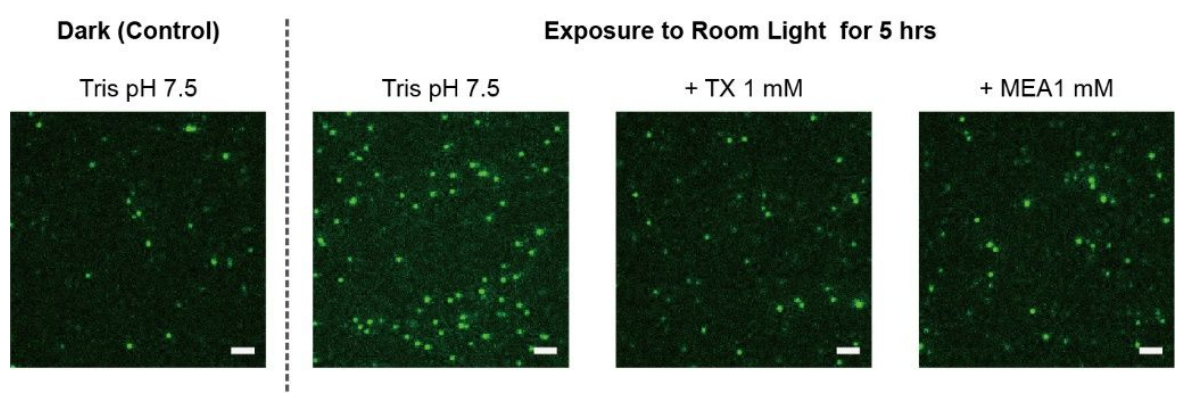

Figure S18. Representative images of preformed $\mathrm{Cy} 3$ in the green channel.

The images are obtained in the green channel without photoconversion. Either $1 \mathrm{mM}$ TX or MEA was added to the DNA stock solution before exposure to ambient light. The triplet-state quencher additives inhibit the ambient light-induced photoconversion of Cy5. Scale bar, $2 \mu \mathrm{m}$. Note that the additives did not affect the DNA hybridization efficiency. 


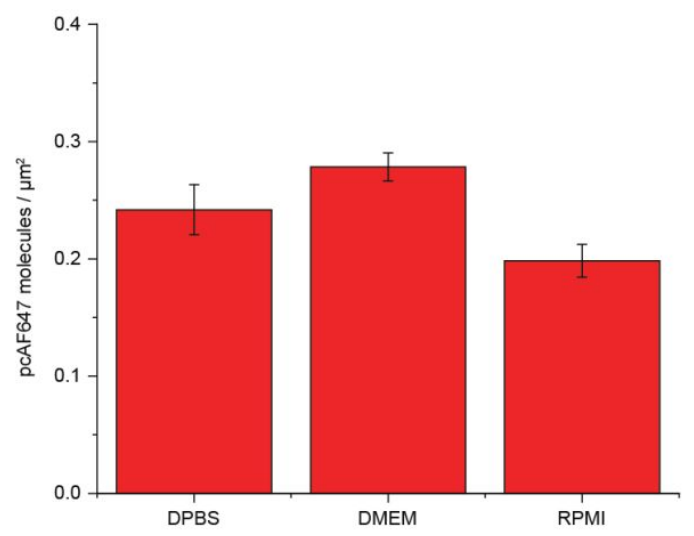

Figure S19. Photoconversion rate difference of AF647 in various culture media when used to immunostain fixed HeLa cells.

AF647-conjugated EGFR antibody was used to label fixed HeLa cells, and AF647 was converted with a 642 $\mathrm{nm}$ laser in various culture media conditions: DBPS, DMEM and RPMI (number of cells $=10$ per condition). 


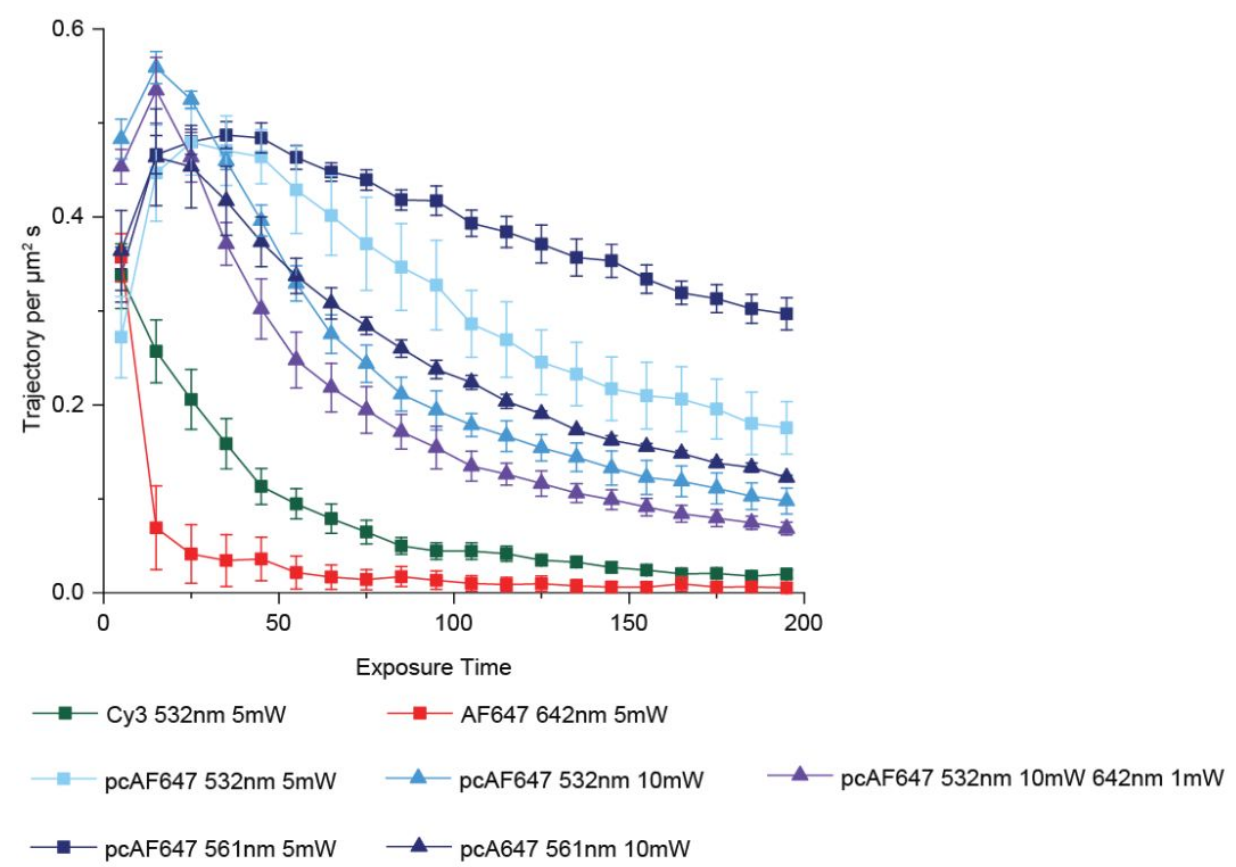

Figure S20. Numerous laser lines with different powers and wavelengths were used to illuminate AF647immunostained SKBR3 cells.

Numerous laser lines were used to illuminate AF647-immunostained SKBR3 cells, and the density of the pcAF647 trajectory was observed for 200 seconds of continuous illumination. Data for Cy3 and AF647 are shown together (number of cells $=3$ per condition). AF647 or Cy3 was conjugated to ErbB2 antibody, and the antibody concentration was controlled to have a similar density of dyes in the first stage of time. A $5 \mathrm{~mW} 561$ $\mathrm{nm}$ laser showed a steady trajectory density due to similar numbers of converted AF647 and bleached pcAF647 molecules. 

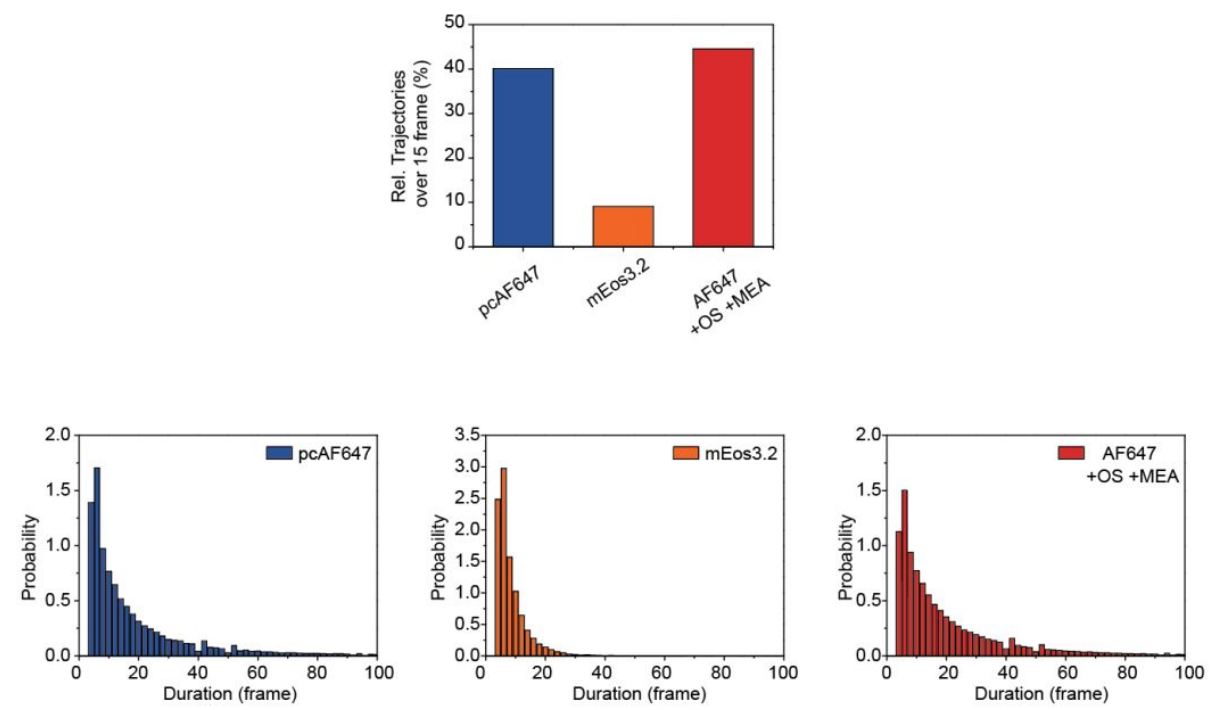

Figure S21. Comparison of fluorophore trajectory length between pcAF647 and fluorophores commonly used in a typical super-resolution technique.

The trajectory length of pcAF647 is compared to the trajectory length of mEos3.2 (commonly used in sptPALM) and AF647 in an oxygen scavenged system (commonly used in STORM). The upper panel shows the ratio of the number of long trajectories ( $>15$ frames) to the total number of trajectories acquired. The lower panels show histograms of the trajectory lengths of the three fluorophores. The frame rate is $50 \mathrm{~ms}$ per frame. The area of probability is normalized to 1 . 
a


b
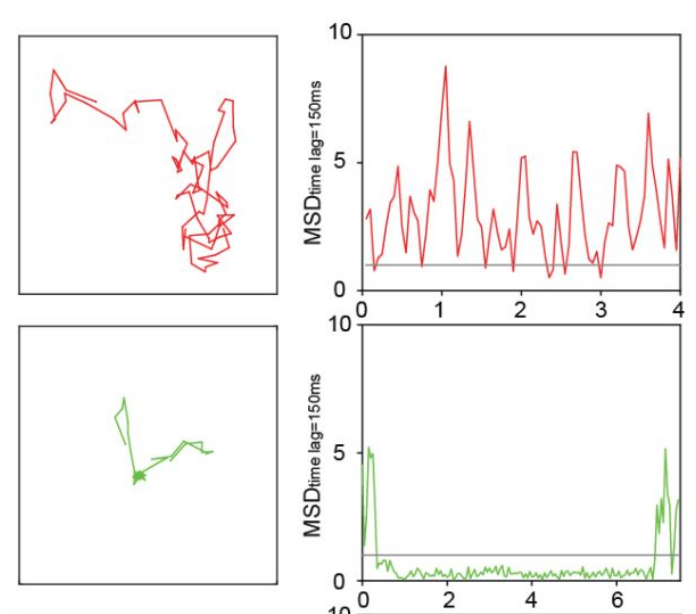

c
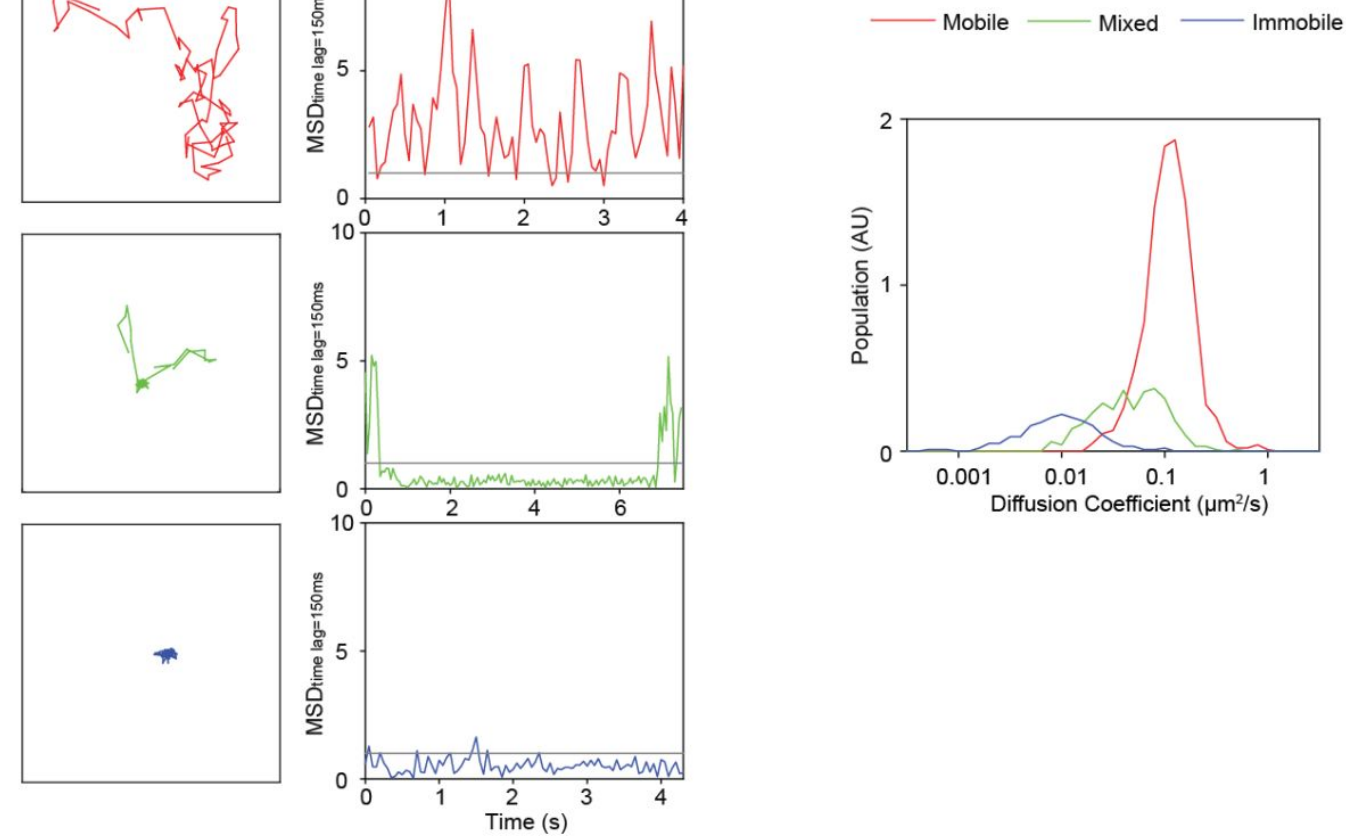

\section{Figure S22. Classification of trajectories in live cell tracking}

(a) Acquired trajectories from live cell tracking exhibiting various forms of diffusive behavior. Trajectories are classified into three groups: mobile, immobile and a mix of the two. Scale bar, $0.5 \mu \mathrm{m}$. (b) The left panel shows a representative image of trajectories for each group. The right panel shows sorting of each trajectory by calculating the MSD for a time lag of $150 \mathrm{~ms}$ and comparing every three consecutive MSDs with $2 \times$ localization error (gray line indicates $2 \times$ localization error). (c) Diffusion coefficient population of three groups in single HeLa cells is shown. 
a



b



\section{Figure S23. Population change of classified trajectories in live cell tracking}

(a) AF647-conjugated EGFR was observed for 30 minutes by single-particle tracking. At each time point, about 10,000 trajectories were obtained in 40 seconds of acquisition with a $50 \mathrm{~ms}$ frame rate. From the collected trajectories, only trajectories with durations of more than 10 frames ( 2000 trajectories) were sorted into three different categories: mobile, mixed and immobile. The sum of trajectories in each population at 0 min was set to $100 \%$. (b) The ratio of classified trajectories is calculated by dividing the number of the total trajectories in the each time point. The ratio of each population stays constant for $30 \mathrm{~min}$ of the observation time. 
Movie S1. Single-particle tracking of AF647, Cy3 standard, and pcAF647 without additives in living cells.

ErbB2 in SKBR3 cell was labeled with ErbB2 antibody conjugated with AF647 (left), Cy3 standard (middle), and AF647 (right), respectively. Imaging was performed in phenol red-free DMEM culture media without additives, such as reducing agents and oxygen scavenging agents. Each movie shows three consecutive streams of 200 frames with a $50 \mathrm{~ms}$ frame rate, i.e., 600 frames in total. The region of interest in each movie was 44.4 $\mu \mathrm{m}$ by $44.4 \mu \mathrm{m}$. The measurement for pcAF647 was performed with a $561 \mathrm{~nm}$ laser, while Cy3 and AF647 were illuminated with $532 \mathrm{~nm}$ and $642 \mathrm{~nm}$ lasers, respectively. The laser powers were $5 \mathrm{~mW}$. ErbB2 was immunostained at different concentrations to give a similar density of fluorophore in the first time window. The densities of AF647 and Cy3 standard signals decay as they bleach under laser illumination, while the density of pcAF647 increases during $0-10 \mathrm{sec}$ and then the density remains constant due to continuous conversion of the fluorophore. After the photobleaching of the fluorophores, AF647 and Cy3 standard signals appear only on the edge of the cells due to the diffusion on the cell membrane. 